\title{
JUVENTUDES ENTRE O RURAL E O URBANO: O CASO DOS AGROBOYS E AGROGIRLS DE BELA VISTA DE GOIÁS
}

\author{
Andréa Vettorassi* \\ Lorrany dos Santos Ferreira** \\ Flávio Munhoz Sofiati* \\ *Universidade Federal de Goiás, Faculdade de Ciências Sociais, Goiânia, GO, Brasil \\ **Universidade Federal de Goiás, Programa de Pós-graduação em Sociologia, Goiânia, Goiânia, GO, Brasil
}

\begin{abstract}
Resumo
O texto faz uma análise de jovens em seus contextos de ruralidade na perspectiva de compreender como esse grupo social, seja de origem urbana, seja rural, vivencia os aspectos culturais do universo rural em Bela Vista de Goiás, uma cidade de base econômica agrícola. A juventude estudada é caracterizada, com base em sua roupagem modernizante, como agroboys e agrogirls por ser influenciada pelo country estadunidense, pelo agronegócio e pela indústria cultural brasileira, evidenciando sua existência entre o rural-urbano e entre campo-cidade. Foram identificadas algumas concepções do grupo estudado, estudantes do Ensino Médio, sobre o campo e a cidade, a relação com o trabalho, suas origens, práticas de lazer e perspectivas profissionais. Concluiu-se que esses jovens vivem a lógica da modernidade e o ideal de mundo globalizado, com predomínio da negação do projeto de camponês, que é atrelado às representações do caipira e atrasado, e a produção de uma forma modernizante da vivência do rural.

Palavras-chave

Juventude; Rural; Bela Vista de Goiás; Agroboy/Agrogirl.
\end{abstract}




\title{
YOUNG PEOPLE BETWEEN THE RURAL AND THE URBAN: THE CASE OF THE AGROBOYS AND AGROGIRLS IN BELA VISTA DE GOIÁS
}

\author{
Andréa Vettorassi* \\ Lorrany dos Santos Ferreira* \\ Flávio Munhoz Sofiati* \\ *Universidade Federal de Goiás, Faculdade de Ciências Sociais, Goiânia, GO, Brazil \\ **Universidade Federal de Goiás, Programa de Pós-graduação em Sociologia, Goiânia, Goiânia, GO, Brazil
}

\begin{abstract}
The text undertakes an analysis of young people in their rural contexts from the perspective of understanding how this social group, whether of urban or rural origin, experiences the cultural aspects of the rural universe in Bela Vista de Goiás, a town with an agricultural-based economy. The young people studied are characterized, due to their modernized way of dressing, as "agroboys" and "agrogirls", having been influenced by the North American country and western style, by agribusiness and by the Brazilian cultural industry, thereby evidencing their existence between the rural-urban and the countrysidecity. Certain conceptions of the studied group, all high school students, were identified, regarding the countryside and the city, their relationship with work, their origins, leisure practices and professional perspectives. It was concluded that these young people are living the logic of modernity and the ideal of a globalized world, with a predominant denial of the peasant project, which is linked to representations of the caipira-a yokel, of being backward, and to the production of a modernized way of living the rural.
\end{abstract}

Keywords

Youth; Rural; Bela Vista de Goiás; Agroboy/Agrogirl. 


\title{
JUVENTUDES ENTRE O RURAL E O URBANO: O CASO DOS AGROBOYS E AGROGIRLS DE BELA VISTA DE GOIÁS
}

\author{
Andréa Vettorassi \\ Lorrany dos Santos Ferreira \\ Flávio Munhoz Sofiati
}

Introdução

O presente artigo trata da juventude contemporânea, especialmente no contexto da ruralidade. Bela Vista de Goiás tem 28.077 habitantes, 4.223 deles entre 15 e 24 anos, segundo dados do Censo do Instituto Brasileiro de Geografia e Estatística (IBGE) de 2016. Busca-se compreender como os jovens dessa cidade pertencentes à cultura juvenil (PAIS, 1993) ${ }^{1}$ dos agroboys e agrogirls, vivenciam e representam o rural e o urbano. De modo geral, o objetivo é discutir como esses sujeitos concebem a cultura atual sobre os moldes do campo e da cidade, deixando evidente a maneira como integram e interagem nesses espaços que, mais do que o urbano ou o rural, representam uma dualidade campo-cidade. Portanto, a análise procura compreender as dinâmicas construídas por esses jovens goianos pautada em suas construções identitárias híbridas (HALL, 2000) ${ }^{2}$, especialmente no que se refere às concepções urbano-rurais.

A juventude é uma categoria social construída por meio de múltiplas representações e interpretações sociais. Assim, trata-se de um conceito que supera as definições biológicas e etárias, devendo ser analisada como, “[...] ao mesmo

\footnotetext{
1. As culturas juvenis são entendidas como "práticas sociais" dos jovens "no interior dos ritmos da vida cotidiana". "Por culturas juvenis, em sentido lato, pode entender-se o sistema de valores socialmente atribuídos à juventude (tomada como conjunto referido a uma fase da vida), isto é, valores a que aderirão jovens de diferentes meios e condições sociais” (PAIS, 1993, p. 69).

2. Trata-se de uma "combinação de elementos culturais heterogêneos" que possibilita a constituição de uma "nova síntese" (HALL, 2000, p. 93).
} 
tempo, uma fase da vida, uma força social renovadora e um estilo de existência" (FORACCHI, 1972, p. 302). Além disso, incorpora-se a abordagem de Groppo (2000), que a entende como "elo" e "transição" da fase juvenil para a vida adulta. Entendese, portanto, que a juventude contemporânea é diversa e influenciada diretamente pelas condições histórico-sociais em que estão inseridas (NOVAES, 2000). Ela é fruto das relações econômicas, históricas e sociais do qual fazem parte e, principalmente no contexto goiano estudado, levam-se em consideração tanto a dimensão simbólica como os aspectos fáticos e materiais nos quais a produção social da juventude é construída.

O texto foca sua análise nos estudantes do Ensino Médio do Colégio Estadual Pedro Vieira Januário, em Bela Vista de Goiás. São jovens que estudam em período integral. Todos os 165 alunos do Ensino Médio matriculados em 2018 nessa escola foram entrevistados. A escolha por essa instituição se deve ao fato de ser a única escola de nível médio na cidade com a modalidade integral, o que altera significativamente a relação dos entrevistados com a escola e com a zona urbana do município. ${ }^{3}$ De modo geral, eles vivem o ritmo de uma cidade interiorana, mas que, em face da proximidade com Goiânia (45 km), a capital do estado de Goiás, apresenta dinâmicas culturais que mesclam ruralidade e urbanidade. Esse município é desenvolvido economicamente sobre fortes bases agrárias, o que contribui na formação da identidade desses sujeitos.

O caminho metodológico percorrido para o desenvolvimento do trabalho foi a pesquisa com base em survey (FONSECA, 2002) ${ }^{4}$, especificamente por meio de aplicação de questionário, e a observação participante, realizada por uma das pesquisadoras, coautora do artigo, que é professora de Ensino Médio em Bela Vista de Goiás. Os jovens estudados, para um efeito comparativo e distintivo, foram divididos em dois grupos: os jovens em um primeiro momento denominados urbanos, pois são os que residem na cidade, e os jovens rurais, aqueles que residem no campo e migram diariamente para a cidade a fim de ir à escola. As questões que compunham os questionários eram relativas às realidades sociais de cada um: a relação com o trabalho, a origem (campo-cidade), a família, as práticas de lazer e o futuro profissional. O objetivo do questionário, aplicado por uma das autoras

3. Segundo dados do IBGE, havia, em 2018, 967 jovens matriculados no Ensino Médio em Bela Vista de Goiás, em escolas públicas e privadas. O município conta com duas escolas públicas e três escolas particulares que oferecem esse nível de ensino. Isso significa que a pesquisa ora apresentada contou com a resposta de $17 \%$ do número total de estudantes matriculados no Ensino Médio do município de Bela Vista de Goiás e de 100\% dos matriculados na modalidade integral.

4. A pesquisa com survey pode ser assim definida: "a obtenção de dados ou informações sobre as características ou as opiniões de determinado grupo de pessoas, indicado como representante de uma população-alvo, utilizando um questionário como instrumento de pesquisa” (FONSECA, 2002, p. 33). 
ao longo de quatro dias e sob a supervisão da coordenadora pedagógica da escola, foi alcançar as representações e o imaginário que os jovens conferem ao universo rural contemporâneo.

Algumas questões nortearam o estudo: quais as construções desses jovens quanto à agricultura familiar e ao agronegócio? Qual o perfil daqueles que vivem o urbano e o rural na mesma espacialidade? Estes representam uma nova tipologia de goianos "modernos”, que "negam” a tradição caipira de Goiás? Quais são as influências para a construção da identidade dos jovens que são rurais e urbanos ao mesmo tempo?

\section{Juventude rural moderna}

A diferenciação e a distinção entre rural e urbano constituem um desafio em diversos lugares do mundo, visto que "muitos países consideram rurais a localidades abaixo de certo patamar populacional” (ABRAMOVAY, 2000, p. 5). De fato, as definições teóricas fornecem os elementos necessários às formas empíricas de delimitação do espaço quanto às características rurais e urbanas. Ficam evidentes algumas dimensões fundamentais para a distinção entre rural e urbano, a saber: demografia, desenvolvimento econômico e modos de vida. A perspectiva da territorialidade tem ainda uma dimensão metodológica e operacional, tanto no campo das políticas de desenvolvimento rural como nas novas formas de delimitação entre rural e urbano. No caso brasileiro, segundo a regra oficial do IBGE, o espaço rural abrange as áreas externas ao perímetro urbano legalmente definido.

No entanto, emerge a necessidade de definir o rural e o urbano por outro viés, que não o puramente demográfico, apesar do reconhecimento da praticidade que esse critério oferece, visto haver muitas imprecisões que constituem enormes desafios para os pesquisadores dessa temática, a começar pela diferenciação entre práticas que sejam exclusivamente do mundo rural e do mundo urbano. As concepções de rural e urbano têm sido debatidas pela academia e pelas agências de fomento de políticas públicas, preocupadas em repensar o próprio conceito de ruralidade na contemporaneidade com base nas singularidades do contexto brasileiro (MIRANDA; SILVA, 2013).

Entende-se que mais importante do que restringir a análise à classificação rural/urbana é compreender as relações que se estabelecem entre os sujeitos dessas espacialidades, a fim de identificar os elementos presentes no espaço que se pretende analisar. É necessário também considerar que toda realidade é dotada de uma dinamicidade que pode tornar os conceitos ultrapassados e obsoletos. Assim, a apreensão do movimento da realidade em uma perspectiva histórica deve ser prioritária em relação à definição estrita do que é rural e do que é urbano, uma 
vez que "o campo e a cidade são realidades históricas em transformação tanto em si próprias quanto em suas inter-relações” (WILLIAMS, 1989, p. 387). Nesse sentido, a chave para entender a temática neste artigo passa pela caracterização do jovem rural vinculado à cultura dos agroboys e das agrogirls.

Nessa perspectiva, o reconhecimento do rural deve basear-se na concepção de que ele não pode ser definido por oposição, mas em sua relação com as cidades, daí a necessidade de atentar sempre para a manutenção de suas especificidades. A ênfase às particularidades e singularidades que marcam tanto o rural como o urbano é verificada nos estudos de João Rua (2005), que apresentam uma visão mais integradora ancorada em uma abordagem mais territorial, ou seja, fundamentada nas territorialidades em que o urbano e o rural se mesclam. Segundo esse autor, a identidade do rural contemporâneo pode ser apreendida com base na consideração de uma série de “mistos”, já que o rural de hoje não é mais o rural "pleno” de algumas décadas. A incorporação de "urbanidades”, entendidas como a manifestação de elementos urbanos no campo, produz uma interação que dá lugar a territorialidades ímpares, que restam ser definidas e, mais importante, compreendidas.

Todavia, o rural continua sendo visto como símbolo do atraso e da ausência de cultura, apesar de estar cada vez mais inserido no contexto da modernidade, enquanto o urbano representa para muitos o auge civilizatório, sustentado em uma noção - decorrente dos ideais iluministas e ainda muito presente em parte da produção nas ciências humanas - essencialista e unidirecional de cultura que conduz à ideia de que há um único caminho cultural cujos pontos de partida e de chegada são, respectivamente, as culturas consideradas "primitivas” e a culturas consideradas “civilizadas”.

Por isso, é oportuno salientar que a contraposição urbano-rural vai muito além da diferenciação entre cidade e campo e que estes não podem ser identificados como dicotômicos, já que a modernização da sociedade engendrou transformações profundas e não só estreitou como intensificou as relações sociais estabelecidas entre eles. Nesse sentido, ressalta-se a necessidade de que o urbano e o rural precisam ser encarados como interdependentes e complementares, nos pontos em que se mesclam, formando um híbrido.

Essa configuração influencia a própria identidade dos indivíduos, concebida a partir de sistemas culturais. Assim, identidade seria um conceito pensado com relação ao "sentimento de pertencimento de realidades" e a um "conjunto de significados compartilhados” (HALL, 2000). Nessa perspectiva, a identidade é compreendida como algo formado culturalmente, um posicionamento e não uma essência, ligado à discussão das identidades culturais, nacionais e aquelas que se formam por sentidos cambiantes e contínuos do cotidiano do sujeito (HALL, 1996). 
A perspectiva de Hall (1996) colabora para o entendimento dos jovens estudados neste trabalho, os quais podem ser considerados "sujeitos pós-modernos" - ou seja, são indivíduos fragmentados e possuidores de várias identidades contraditórias ou não resolvidas, o que implica que o sujeito assume identidades diferentes em momentos diferentes. Esses jovens não apresentam mais uma identidade fixa, dependendo de estarem no contexto da zona rural ou da zona urbana. Dessa forma, na medida em que ocorrem mudanças também na zona rural, onde os sistemas de significação e representação cultural se multiplicam, o jovem rural se vê diante de muitas identidades, as quais ele é capaz de assumir, tornando-se um indivíduo não só centrado no seu "eu" interior, nem formado exclusivamente pela relação com outras identidades. Trata-se de uma mistura de identidades, e, em certos momentos, o jovem privilegia uma delas e, em outros, privilegia as demais (PREDIGER, 2009).

É nesse registro que se apresenta a configuração dos jovens de Bela Vista de Goiás, estudantes de um colégio estadual no módulo integral, com uma pesquisa pautada na figura dos agroboys e das agrogirls. Faz-se necessário frisar que diversos estereótipos, estigmas e preconceitos permeiam a caracterização dos jovens rurais no Brasil contemporâneo, o que acarreta várias questões, como sua permanência no campo e a busca por um futuro sem as atribuições de adjetivos pejorativos, como "caipiras" e "roceiros" como sinônimos de "atrasados”. Diante dessa realidade, tem-se uma nova construção social da juventude caipira sobre os aspectos culturais do padrão country, o que os leva a vivências de um modo de ser e de se identificar como agroboy/agrogirl.

Considera-se, inicialmente, que o estado de Goiás, em seu histórico econômico-social, apresenta aspectos ligados à agricultura e à pecuária, o que remete a um modo de vida fundamentado na ruralidade. E tais aspectos culturais, por vezes, são vivenciados em contextos urbanos. Assim, entende-se que esses jovens, rurais e urbanos de Goiás, são marcados por costumes característicos, por vezes compartilhados por meio da música, do vestuário e da linguagem. Mas também é preciso levar em conta que, com a reformulação dos aspectos sociais e a nova dependência econômica resultante do processo de industrialização no país, ocorreram mudanças no espectro econômico, no social e no cultural da vida "caipira" tradicional. Essa visão é resultante de um processo de industrialização que culminou numa valorização de padrões estrangeiros, como o country, presentes, por exemplo, no sertanejo universitário, amplamente consumido no estado de Goiás.

Assim, em conjunto com a fragmentação do indivíduo, que possibilita inclusive a recomposição dos sujeitos em composições híbridas que ressignificam e articulam formas clássicas e modernas, a identidade rural está assumindo novos traços: o caipira ganhou novo status: o cowboy se mostra como aquele sujeito que 
ostenta seus bens, que tem escolaridade, que não se sente inferior, que é livre, bruto, que arrisca a vida em busca de liberdade (SETUBAL, 2005). Esse caipira chegou à cidade em outros moldes; foi se acomodando a diferentes padrões culturais, os quais remetem a uma lógica modernizante. Mas, segundo Antonio Candido (2010), os aspectos modernos não substituíram os tradicionais, pois ocorreu um processo de ajustamento entre esses valores.

Deve-se considerar imprescindivelmente, então, que o rural contemporâneo é uma cultura semelhante a qualquer outra cultura transformada, que desenvolveu modos de ser e de fazer não mais ligados estritamente às atividades oficiais e não oficiais do campo; que resiste ao desaparecimento do rural ao crer nas tradições e na maneira própria de viver urbanizada; que mantém diferentes formas de negociação com os produtos da cultura de massa e com a cultura urbana dominante, capaz de modificar posicionamentos, organizar experiências e fazer emergir outros sentidos diante de sua nova condição. Por isso, a noção que deve ser enfatizada é que o rural se constrói sempre em constante relação com as culturas dominantes e hegemônicas, com o mundo urbano (a sede municipal, a capital do estado, a cidade média ou grande cidade próxima etc.), sem abandonar, porém, características do rural, dando novo significado a elas.

Compreende-se, portanto, que o rural vem sendo ressignificado na sociedade com base nas tradições oficiais (danças, músicas, comidas típicas, artesanatos), nas imagens dessas tradições e em suas reelaborações nos produtos da cultura de massa (na música, no vestuário, na propaganda, no cinema etc.). Em outros termos, o rural sempre é "relacional", ou seja, mantém relações com o urbano e com as influências da cultura dominante e da comunicação de massa.

Nesse sentido, numa disputa com uma construção narrativa e hegemônica, reconstrói-se uma percepção do rural que não estaria mais ligada à rusticidade, ao atraso e à simplicidade, a símbolos como o caipira ou o roceiro. A nova ruralidade seria referendada por meio da estética do agroboy e da agrogirl, revestidos de símbolos do poder, do capital e da distinção triunfando sobre uma imagem do rural negativamente estereotipada.

São várias as conceituações e terminologias que dão aporte teórico às discussões sobre a juventude e seus padrões de sociabilidade e construção identitária na sociedade globalizada. No entanto, considera-se que os sujeitos desta pesquisa compõem o que pode ser denominado culturas juvenis (PAIS, 1993). De fato, o que se propõe analisar são as representações culturais e simbólicas dos jovens ao experienciar e compartilhar valores identificáveis com a cultura dos agroboys e das agrogirls. 
A terminologia "agro" pode definir os sujeitos conectados ao mundo rural, com o uso dos termos estrangeiros boy e girl remetendo à cultura estadunidense, assim como acontece com os termos country e cowboy. É importante informar que não se pretende enviesar a pesquisa ao gênero masculino, com enfoque restrito aos agroboys. Todavia, em vista da construção social acerca da presença masculina nos contextos rurais, em vários momentos o debate é direcionado aos jovens do sexo masculino.

Nesse contexto, o representante do gênero masculino ambientado na ruralidade, embora associado ao atraso e à caracterizado de "roceiro", é compreendido como um sertanejo estereotipado de "macho", um homem viril, forte e que representa a relação de poder econômico permeado com valores burgueses. A masculinidade se torna essencial para a construção dessa identidade cultural, numa constituição em que há pouco espaço para o feminino, de modo que estas, muitas vezes, são estereotipadas como "mulher macho". Assim, há no contexto da ruralidade uma construção social que enfatiza o pertencimento ao universo masculino.

Numa perspectiva idealizada, o agroboy é aquele homem, jovem e rico, nascido e criado em grandes propriedades rurais e que se dedica aos prazeres e à vida recreativa. São “os novos caipiras”, que assumem uma "roupagem” inspirada no estilo caipira estadunidense, uma representação estereotipada que reforça a dualidade entre atraso e modernidade.

Ao discutir as construções culturais desse grupo, é imprescindível estabelecer correlação com a música, um veículo de informação que traz em si toda transformação efetivada pela indústria que a comercializa. É evidente que sobretudo os jovens contemporâneos consomem músicas que se consolidaram no meio urbano e se tornaram um produto da indústria cultural (ADORNO; HORKHEIMER, 1985). Nesse contexto, Edson Farias (2005, p. 647) evidencia como “[...] o lazer e o entretenimento interferem no plano dos valores e das expressões, com efeitos sobre a ressignificação de domínios de memórias”. Segundo Ortiz (2006), é possível compreender as problemáticas que envolvem as relações entre economia e cultura no mundo contemporâneo. A noção de "modernidade-mundo" do autor pode ser útil para a análise de questões ligadas à identidade de diversidade cultural.

A música sertaneja, entretanto, é compreendida como um produto da indústria cultural. Antes de adentrarmos essa questão, é necessário distinguir música caipira e música sertaneja. A primeira, mais expressiva no Sudeste e Centro-Oeste do país, tem características fundamentais que a diferenciam da música sertaneja. Em seu contexto de surgimento, a música caipira não se limitava apenas à questão da música em si; ela se integrava a toda a cultura caipira, ao contemplar lazer, atividades cotidianas e religiosas, com o papel de elemento integrador da comunidade 
em que estava inserida. Ademais, dava suporte ao imaginário comum dos habitantes da mesma região, colaborando para a manutenção social e cultural da comunidade. Assim, a música caipira pode ser entendida como uma expressão cultural que se integra no contexto do sujeito da zona rural ou do interior. Em geral, suas temáticas são ligadas a religião, lazer, formas de trabalho e sociabilidade do dia a dia do camponês.

A música sertaneja, por seu turno, caracteriza-se por assimilar aspectos da cultura caipira em um formato destinado ao mercado e transformando o que é próprio do conteúdo rural para o urbano, como é perceptível nas duplas que representam o sertanejo universitário, estilo musical consumido em todo o país. Essa consolidação tomou proporções maiores com o surgimento de duplas sertanejas, as quais vendem uma nova forma de ver o caipira, aliando a isso instrumentos de última geração que conferem um arranjo mais elaborado às canções, além de influências dos cowboys estadunidenses, no que diz respeito ao vestuário.

Dessa forma, o sertanejo incorporou características da indústria cultural e, com o passar das décadas, tornou-se, em decorrência da popularidade atingida e da agregação de novos ritmos e técnicas, o primeiro gênero de massa mais consumido no país. Nessa conjuntura entre a música caipira e a música sertaneja surgiu o gênero sertanejo universitário. Esse estilo musical, que despontou em meados de 1992, ressalta a realidade do jovem contemporâneo: festas, bebidas alcoólicas, símbolos sexuais e dinheiro. Oriundos das universidades, os jovens que apreciavam o sertanejo que imperava até aquele momento introduziram uma nova "roupagem" em todo o universo sertanejo.

As representações desse novo gênero incitam comportamentos e dão ênfase ao dinheiro e aos indicadores de riqueza e consumo. É comum, por exemplo, o destaque dado por essas composições ao carro como elemento central na conquista de mulheres. Ou seja, nessas letras, em que o carro é apontado como signo de riqueza e poder, as conquistas sexuais são apresentadas como resultado da ascensão social, simbolizada pelos carros potentes, pelas roupas de marcas e pelo estilo de vida pautado na ostentação de bens de consumo. Essas composições receberam, inclusive, a alcunha de "sertanejo ostentação"5.

Por isso, compreende-se que os agroboys e as agrogirls são jovens contemporâneos que vivem as dinâmicas culturais da urbanidade e da ruralidade, porém no contexto da indústria cultural, influenciados, sobretudo, pela música sertaneja

5. Há muitas reportagens sobre o estilo. Uma delas é "Sertanejos que estouraram cantando músicas sobre carros”, São Paulo, Rede TV, 5 out. 2015. Seção Celebridades. Disponível em: https://www.redetv. uol.com.br/tvfama/blog/celebridades/sertanejos-que-estouraram-cantando-musicas-sobre-carros. Acesso em: 10 dez. de 2020. 
universitária e pelos padrões que ela direta ou indiretamente incita. Pautados num padrão de sociabilidade experimentado nas cidades, esses jovens ressignificam as representações dos caipiras tradicionais, formando, assim, uma nova geração de indivíduos rurais que são "modernos" e escolarizados e que se vestem de acordo com a moda e vislumbram o poder econômico ligado ao agronegócio.

\section{Jovens de Bela Vista de Goiás}

O município de Bela Vista de Goiás, distante $45 \mathrm{~km}$ da capital do estado de Goiás, é considerado parte da região metropolitana de Goiânia. Situada na região Centro-Oeste do país, sua população é de, aproximadamente, 28.077 habitantes (IBGE, 2016). Segundo a narrativa local, a cidade surgiu perto dos centros de mineração, onde tropeiros e carreiros que transportavam mercadorias do estado de Minas Gerais para o de Goiás fizeram do local ponto de pouso e de "rancho dos tropeiros", circundando-o. Assim surgiu o povoado, que, tempos depois, em 5 de junho de 1896, foi elevado à categoria de município.

As atividades rurais sempre foram a base econômica do município. Durante muito tempo, a atividade de destaque foi o fumo cultivado e processado - por sinal, o principal produto de exportação durante décadas. Entretanto, a partir de 1980, a agropecuária passou a ocupar lugar de destaque na região, o que levou Bela Vista de Goiás a ser classificada, alguns anos mais tarde, como a segunda maior bacia leiteira do estado.

Atualmente, grande número de proprietários de terras exerce atividades agrícolas, mas é importante mencionar a influência econômica de algumas indústrias no município. Trata-se de um dos maiores criadores de gado leiteiro do estado, e nele estão instalados três estabelecimentos leiteiros, dois postos de recepção e resfriamento e um laticínio com usina para pasteurização. A avicultura, além de gerar a maior fonte de empregos, contribui para o fortalecimento do mercado e o escoamento das produções de milho, soja e sorgo.

Os sujeitos desta pesquisa, estudantes do Colégio Estadual Pedro Vieira Januário, em Bela Vista de Goiás, são jovens que vivem práticas urbanas, mas que são carregados de traços culturais que os interligam ao mundo rural. Assim, percorrendo as questões que permeiam a realidade deles, suas práticas de lazer, os anseios profissionais, as origens (campo-cidade) e a permanência na cidade ou a possibilidade de migrar para o campo, busca-se visualizar as dinâmicas culturais que são ao mesmo tempo experienciadas e ressignificadas por eles. Trata-se de jovens pertencentes a uma classe social similar, pois estão entre os menos favorecidos do município, mesmo que assumam características da cultura agroboy/agrogirl. 
A primeira distinção diz respeito à identificação do quantitativo de jovens que residiam em áreas rurais, dos que migravam diariamente até a escola e dos que residiam na área urbana. Assim, os dados foram coletados em dois grupos de sujeitos: os alunos rurais (residentes em áreas rurais) e os alunos urbanos. Essa divisão também foi feita quanto à aplicação dos questionários, uma vez que $68 \%$ deles moravam na área urbana e 32\%, na área rural. Os questionários destinados aos jovens rurais continham abordagens relativas à sua realidade no campo, à relação com o trabalho e com a família, às suas práticas culturais, às concepções de lazer, à perspectiva profissional futura e à sua relação com a cidade. Já os questionários aplicados aos jovens urbanos, embora numa mesma perspectiva de abordagem, buscaram o caminho inverso: a relação desses jovens com o campo, com o universo rural. Assim, as questões norteadoras também objetivavam compreender as relações que mantinham com o trabalho e com a família, suas práticas culturais e concepções de lazer, a perspectiva do futuro profissional e, especialmente, a relação com o rural, vivenciando-o quer no espaço rural, quer no contexto urbano. De toda forma, é importante frisar que houve similaridades nas respostas dos dois grupos ao questionário.

Faz-se necessário considerar que as questões juvenis, numa perspectiva bourdieusiana, são entendidas como um conjunto de significados estruturantes e estruturados, elaborados pelos jovens e incorporados por eles. Essas questões nos auxiliam na compreensão do sentido da categoria juventude, por isso não se podem perder de vista as discussões sobre suas concepções a respeito de trabalho, família, lazer, educação e futuro. E a juventude rural também é um produto próprio da cidade, visto que não está isolada do mundo, principalmente após o acelerado processo de urbanização do Brasil.

No tocante ao tema do trabalho, identificou-se que a grande maioria dos estudantes pesquisados não trabalhava. A concepção de trabalho, conforme Marx (1996), é relativa à força de trabalho que esses jovens "vendem” em troca de um salário. Contudo, as informações obtidas não revelam a situação de formalidade/ informalidade das atividades que exercem nem a precariedade do trabalho e seus salários. Nesse sentido, estão sendo considerados trabalhadores aqueles que se autodeclaram como tal e que, supostamente, são remunerados. Porém, para o debate sobre juventude rural, é relevante destacar que a precarização e a informalidade são parte recorrente da vida de jovens no campo. Trabalham sem receber renda, ou por pouca renda, na maior parte das vezes em condições informais.

A pesquisa considerou o tempo de dedicação dos alunos ao trabalho. A maioria dos estudantes moradores das áreas rurais, $79 \%$, declara não trabalhar, ou seja, esses alunos dedicam seu tempo exclusivamente às atividades e ao ambiente 
educacional. Os que declaram serem trabalhadores representam 21\%, e são aqueles que, além de permanecerem o dia todo na escola, ainda realizam alguma atividade quando estão fora do ambiente escolar. Quanto aos jovens que habitam a área urbana, apenas 6\% declararam trabalhar e $94 \%$ não desenvolvem nenhuma atividade trabalhista, com seu tempo dedicado integralmente às atividades escolares. A análise comparativa mostra que a quantidade de jovens rurais que trabalham é maior do que a de jovens urbanos. De fato, percebe-se que os jovens rurais têm uma relação maior com o trabalho quando comparados aos jovens urbanos.

Como é evidente, a maioria desses jovens não trabalha pelo fato de estudarem em tempo integral. Apesar de haver um percentual menor de jovens que trabalham, em ambos os grupos, rural e urbano, é importante destacar a necessidade de acompanhamento em relação ao processo de ensino-aprendizagem: eles contam somente com o período noturno para se dedicarem aos estudos extraclasse e ainda têm que dividi-lo com o trabalho. E, com essa jornada exaustiva, podem vir a ter dificuldades de aprendizagem.

Com efeito, o que se visualiza são situações distintas. Há um grupo representativo na amostra que não precisa preocupar-se com a manutenção econômica, porque sua base é mantida pelos familiares; enquanto outra parcela, por meio do próprio salário, complementa o rendimento familiar e/ou mantém o seu consumo. Desse modo, com base na interpretação dos autores, esses dados ressaltam que, mesmo inseridos no mercado de trabalho, a educação tem extrema importância para os jovens e seus familiares na atualidade, por se tratar de um meio de obtenção de conhecimento para uma construção profissional futura capaz de garantir a subsistência e proporcionar qualidade de vida e autorrealização.

Acerca dos jovens que moram nas áreas rurais e da participação deles nas atividades agrícolas, a pesquisa identificou que 65\% declaram não participar de nenhum processo produtivo, ausentando-se das atividades agrícolas. Portanto, 35\% declaram ter alguma participação. Vale lembrar que o número de estudantes do campo que declaram ser trabalhadores é de $21 \%$. É interessante questionar o que esse grupo compreende por trabalho, visto que as atividades do campo não estão sendo consideradas como tal. Ou seja, entende-se que trabalho é somente aquilo que gera renda.

Logo, pode-se concluir que o trabalho é visto por eles como uma atividade remunerada que pode lhes garantir independência financeira, por isso as ações de "ajudar” ou "participar” de atividades domésticas ou agrícolas não os colocam na situação de trabalhadores. Em consequência, os jovens entendem como trabalho aquelas atividades desenvolvidas por eles próprios, como os chefes do estabelecimento rural, pelo fato de assumirem a gestão, comprarem os insumos e venderem 
produtos, além de, geralmente, conhecerem as condições de produção e de mercado (MENASCHE et al., 1996; ABRAMO, 2007; BRUMER, 2007).

Diante desse contexto, questionam-se o futuro dos jovens e o futuro da agricultura no que se refere à hipótese de que, embora morando em meio rural, optem por outras atividades e outra perspectiva de vida em vez daquelas ligadas à ruralidade no espaço; e, inversamente, aqueles que, vivendo em um ambiente urbano, optem por atividades ou modo de vida diferente dos vivenciados na cidade.

Antes de investigar o que pode fazer com que os jovens permaneçam ou não no campo, é preciso compreender as razões pelas quais eles migram. Conforme Weisheimer (2013, p. 22): “[...] as estatísticas dos processos migratórios demonstraram que o êxodo rural, nas últimas décadas, foi protagonizado principalmente por jovens”. Portanto, cabe refletir sobre o conforto que esse jovem goza em sua moradia, bem como sobre o acesso a redes sociais, internet etc., e a organização de eventos culturais pelos membros da comunidade em que está inserido, pois, tanto para os que gostariam de migrar como para aqueles que gostariam de permanecer no meio rural, ter acesso ao melhor dos dois mundos tem se constituído em um desejo e em uma demanda. $\mathrm{O}$ acesso aos bens e serviços produzidos e disponíveis na sociedade brasileira também é, segundo Wanderley (2009), almejado pelas juventudes que vivem no meio rural.

Historicamente, pode-se afirmar que a migração no Brasil ocorreu em decorrência da expulsão da terra pela falta de condições de sobrevivência, muito mais do que pela atração exercida pelas cidades. Neste caso, o êxodo rural não significa desagrado com o local de origem, e sim a busca por um modo de vida melhor. Por essa razão, o interesse maior deve recair sobre o que os motiva a ficar, e não sobre aquilo que os impele a sair. É fundamental analisar se os jovens rurais querem ir embora e, ao mesmo tempo, descobrir se gostam de viver no campo, de modo que a migração não perpetue a imagem equivocada de rejeição desse espaço (MENEZES, 2012). Assim, perpetua-se a relação entre "gostar do campo" e "não ter vontade de morar na cidade" e, por outro lado, entre "não gostar do campo" e "ter vontade de morar na cidade".

No que tange ao imaginário dos jovens rurais sobre a migração para a cidade, encontram-se os seguintes números: para 65\%, migrar para a cidade não é algo inimaginável; ao passo que, para os 35\% restantes, persiste o desejo de permanecer no campo. Podem ser múltiplos os "fatores de expulsão" e os "fatores de atração" que influenciam diretamente a realidade e, em consequência, o imaginário de cada um deles.

É importante notar que os jovens que almejam migrar, representados pela maioria, ameaçam a sucessão familiar, o que gera a probabilidade de esvaziamento 
do rural num futuro próximo. Ao examinar esse processo no qual a juventude rural assume a perspectiva de não permanecer no campo, diversas motivações para esse comportamento podem ser apontadas, como a baixa expectativa de renda na agricultura camponesa, a busca por melhor infraestrutura, serviços e opções de lazer (REDIN; SILVEIRA, 2012).

Uma das razões para a saída dos jovens do campo rumo à cidade se deve à busca pelo "moderno", o que caracteriza a visão sobre o rural como atrasado ou primitivo, fazendo o jovem desse meio querer entrar nos "moldes" da juventude urbana ("moderna”) para não ser visto dessa maneira (MATOS, 2002). Para isso, muitas vezes ele busca se apropriar de novas tecnologias e do conhecimento acadêmico. Assim, a migração entre os jovens camponeses "pode ser avaliada como negação do projeto camponês” (RENK, 1999, p. 43).

No que diz respeito à migração para o meio rural no imaginário dos jovens que vivem em áreas urbanas, a pesquisa mostra que para a maioria, 66\%, essa possibilidade está longe de ocorrer, pois eles declaram não desejar viver algum dia nos espaços rurais. Porém, 34\% deles manifestaram essa vontade. Questões como essa propiciam uma reflexão sobre os aspectos "atrativos” e "não atrativos” do campo apontados por Brumer (2007), os quais por vezes influenciam o imaginário dos jovens com uma realidade diferente no que se refere à possibilidade de algum dia viver ou não longe da cidade.

Além disso, o histórico de ausência de políticas públicas de juventudes eficientes no Brasil, a dificuldade e a insuficiência dos serviços de saúde e de educação de boa qualidade, bem como o acesso limitado ao lazer, têm reduzido a vontade dos jovens de permanecer na zona rural. A falta de apoio para a criação de alternativas de trabalho e de meios diversificados para a composição de renda aumenta ainda mais a tendência de os jovens deixarem o campo. Não raro eles são incentivados até pelos próprios pais, por estes acreditarem que na cidade os filhos terão oportunidades para concretizar seus sonhos (SILVA et al., 2006). Soma-se a isso o ideário de que a cidade é "moderna" e o lugar da "civilização", e o campo, o lugar do "atraso", dos "roceiros" e "caipiras”.

Para discutir o processo sucessório no campo, deve-se considerar o processo de acumulação do capital no campo brasileiro, visto que na atualidade as possibilidades objetivas de formação de novas unidades familiares de produção são bem escassas em virtude da expansão do capital no campo, o que em certa medida tem expulsado os jovens do meio rural. Por isso, os questionamentos da juventude rural supõem o entendimento de uma dinâmica social dupla. Por um lado, a dinâmica territorial, que relaciona a casa (família), a vizinhança (a comunidade local) e a cidade (o mundo urbano-industrial). Trata-se fundamentalmente dos espaços de 
vida que se entrelaçam e que dão substância à experiência dos jovens rurais e à sua inserção na sociedade. Por outro, a vida cotidiana e as expectativas para 0 futuro são constituídas de uma dinâmica temporal: o passado das tradições familiares, que inspira as práticas e as estratégias do presente e do encaminhamento do futuro, o presente da vida cotidiana, focalizado na educação, no trabalho e na sociabilidade local; e o futuro que se projeta por meio da herança, da sucessão e das estratégias de migração temporária ou definitiva (CARNEIRO; CASTRO, 2007).

Dessa forma, as relações sociais se constroem no presente, movidas pelas tradições familiares e locais no passado, e orientam as alternativas possíveis ao futuro das gerações e à reprodução do estabelecimento familiar. Tais dinâmicas se conectam e emerge um ator social multifacetário que pode ser portador, ao mesmo tempo e paradoxalmente, de um ideal de ruptura e de continuidade do mundo rural. Essa realidade, em certa medida, também se apresenta na pesquisa em voga, de modo que, na análise da trajetória familiar dos jovens estudados, percebe-se um histórico de migração.

Sobre as origens familiares, é visível que existe uma pequena divisão entre aqueles que pertencem a uma geração de camponeses (47\%) e aqueles cujos pais migraram da cidade para o campo (que correspondem surpreendentemente a 53\%), seja por fatores econômicos, de trabalho, familiares ou relacionados à segurança. No entanto, esse dado abre discussão para a questão do êxodo rural, pois, embora exista uma parcela significativa dessa geração camponesa, trata-se de um índice que tem diminuído ao longo do tempo, com as pessoas migrando para a cidade. Esse fenômeno evidencia a perspectiva levantada neste trabalho, de que os dois campos sociais apresentados se mesclam e produzem identidades híbridas, já que os resultados estatísticos da pesquisa de survey ora apresentada não são compatíveis com os dados nem com o contexto histórico-demográfico nacional.

Apesar de nascidos e criados na cidade, muitos jovens têm pais de origem camponesa. O maior índice revela aqueles cujos pais são originários do campo, $62 \%$, enquanto os demais $38 \%$ são representados por aqueles cujos pais são oriundos da cidade. É uma questão bastante representativa, pois diz respeito ao processo migratório campo-cidade dos pais que hoje vivem na cidade, mas também dos que viveram na cidade e migraram para o campo. É, portanto, um processo migratório de mão dupla.

De fato, deve-se considerar que a comunicação entre o campo e a cidade facilitou o acesso aos bens e valores urbanos, mas a isso se somam o desemprego e o aumento da violência nos centros urbanos, o que acabou por produzir uma situação em que a vida na cidade se tornou difícil. É nesse contexto que os ideais da juventude apontam para uma síntese, por nós definida como um projeto de vida que articula o rural e o urbano. Abrir novas alternativas de trabalho no campo é 
um projeto que surge em função da perspectiva de estreitamento dos laços com a cidade, favorecido pelas facilidades dos meios de comunicação.

Com relação aos jovens da cidade que têm familiares camponeses, o maior índice é caracterizado por $82 \%$, representados por jovens que têm algum membro familiar residente no campo. Já 18\% declararam não ter familiares nessa situação. É bem representativa a quantidade de jovens que habitam a área urbana da cidade cujos familiares ainda moram no campo, o que nos permite afirmar que, mesmo morando na cidade, muitos jovens têm uma relação parental com camponeses.

Um aspecto importante para entender os jovens estudados diz respeito ao tema do lazer, prática na qual sujeitos buscam realizar atividades agradáveis e de realização individual. Os momentos de lazer são importantes para os jovens, visto que "[...] os espaços do lazer e da cultura são os espaços em que os jovens podem processar suas experiências mais significativas” (SOUZA, 2009, p. 33). Sobre os nossos sujeitos de pesquisa, quando se trata das vivências de lazer, os jovens do campo se revelam bem divididos: 50\% representam aqueles para os quais as atividades de lazer são, em sua maioria, praticadas na cidade, como a ida a bares e shows e visitas a casas de amigos. Já os outros 50\% são representados pelos jovens do campo para quem o ambiente rural é o espaço em que desfrutam da maior parte de seu lazer. Esse fator se torna importante na medida em que, em muitas literaturas, um dos principais motivos que impulsionam os jovens do campo a migrar para cidade é a pouca atratividade dos espaços rurais, especialmente quando se adicionam a esse fenômeno as atividades de lazer.

Para muitos jovens que vivem na cidade, o campo é o lugar onde desfrutam de seu momento de lazer. Quando perguntados sobre esse ponto, 54\% apontaram o campo como opção, em atividades como cavalgadas, pesca e visitas a familiares em sítios. Já para $46 \%$ deles o campo não se apresenta como opção aproveitável para o exercício de atividades prazerosas.

O campo está relacionado com uma forma natural de vida, de paz, de inocência baseada em virtudes simples (WILLIAMS, 1989). Já a cidade é associada à ideia de um centro de realizações, de saber, comunicação e energia elétrica. Mas também se criou uma mentalidade com associações negativas aos termos: cidade como lugar de barulho, de vida mundana e de ambição demasiada; o campo como o lugar de atraso, de pessoas mais ignorantes e de limitação de oportunidades.

Tendo isso em vista, o campo é identificado como espaço de lazer e descanso para aqueles que residem na cidade. O lazer no meio rural apresenta algumas possibilidades, e uma delas é o rompimento com as rotinas, seja da parte de moradores do campo, quando o lazer os distancia de suas tarefas laborais cotidianas, seja da parte dos moradores da cidade à procura de atividades alternativas do meio urbano. 
Alguns jovens, mesmo morando na cidade, mantêm alguma relação com o campo, tanto em razão de questões relativas a trabalho e família como por lazer. Quando perguntados sobre a frequência com que se dirigiam ao ambiente rural, o maior índice foi dos que raramente o frequentam, 45\%. O segundo maior índice foi daqueles que "nunca" frequentam esse ambiente, representados por 20\%; 18\% deles frequentam mensalmente, $15 \%$ semanalmente e $2 \%$ diariamente). Com dados como esses, torna-se possível visualizar o distanciamento dos jovens da cidade em relação ao espaço rural. Entretanto, eles também enfatizam a ausência de um contato direto com o ambiente rural. Verifica-se um contato indireto, reforçando que suas experiências e modos de vida são construídos em uma perspectiva urbana.

No que concerne às projeções profissionais, para os sujeitos em foco a dimensão profissional é importante e tem lugar privilegiado na discussão sobre o futuro. Consideravelmente, é por meio dessas perspectivas profissionais que os jovens constroem seus projetos. Porém, é essencial destacar que não se devem limitar seus percursos de vida apenas às profissões; também é preciso problematizar outras dimensões da condição humana, como as escolhas afetivas, os projetos coletivos e as orientações subjetivas da vida individual. Contudo, para a construção empírica deste estudo, leva-se em consideração a perspectiva futura dos jovens, porque acreditamos ser relevante para a análise e para as discussões contemporâneas sobre o tema.

É nesse contexto que a educação escolar e o futuro profissional se relacionam. Embora a importância da escola esteja além de seu papel como meio facilitador de acesso ao mercado de trabalho, infere-se que o interesse pela educação sempre se associa com o trabalho, porquanto os jovens consideram a escola imprescindível para a obtenção de um bom emprego no futuro (CHARLOT, 2006). No contexto da pesquisa evidencia-se o mesmo interesse, visto que, para os jovens do Colégio Estadual Pedro Vieira Januário, inseridos na modalidade de ensino integral, e com base no que se evidenciou nas respostas dos questionários, existe "uma forte disponibilidade ao estudo, a qual se constitui uma valiosa jazida de competência, de produtividade, de desenvolvimento econômico e social" (CHARLOT, 2006, p. 233).

Essa conjuntura atual, como aponta Paul Singer (2005, p. 28), se justifica pelo fato de que estes "[...] jovens nasceram em um tempo de crise social" e passam por um período de crescente desemprego. Em função disso, existe o medo de "sobrar" no mundo do trabalho, de estarem incapacitados e diante das exigências do mundo atual. Para Regina Novaes (2007), os aspectos do mundo atual que marcam a diferença da condição juvenil em relação a gerações e configurações sociais anteriores estão afetando a juventude e definindo o que é ser jovem hoje, tanto na cidade como no campo. Em complemento, Nilson Weisheimer (2019), ao tratar especificamente 
da juventude rural, evidencia as representações negativas que marcam as práticas profissionais desses jovens no campo. $\mathrm{O}$ autor constata que "[...] esses jovens formam uma comunidade de destino comum em ruptura com o trabalho familiar agrícola, entre outros fatores, porque essa atividade não assegura autonomia material a eles” (WEISHEIMER, 2019, p. 94).

Na síntese das perspectivas profissionais, são muitas as atividades que os jovens rurais estudantes em Bela Vista de Goiás desejam exercer no futuro. Essa questão expõe como, de fato, eles estão impulsionados a manter suas relações com o campo ou rompê-la de alguma forma. Os índices mais expressivos são representados por Medicina Veterinária, correspondente a 18\%, e por Engenharia Civil, também com 18\%; Medicina, 15\%, Psicologia, 9\%; Artes Visuais, Direito e Agronomia, 6\% cada; Odontologia, Pedagogia, Arquitetura, Administração, Fisioterapia, 3\% cada; e 7\% não responderam. É importante observar que, nessa lista, a categoria “Agronomia” teve uma representação de apenas 6\%, o que nos leva à conclusão de que são poucos os jovens rurais que pretendem manter laços com a atividade da agricultura. Portanto, ao indicarem Medicina Veterinária como profissão futura, isso não nos leva a crer que seja no intuito de continuarem arraigados às atividades rurais. Essa escolha profissional aponta mais para a construção de um status "agropecuário" vinculado às práticas e valores urbanos.

De fato, evidencia-se a confluência entre o rural e o urbano, com destaque para a configuração do novo rural a que esses jovens estão submetidos. Com a crescente integração desses espaços e o "atravessamento" do rural pelo urbano (e vice-versa), há exploração e complementaridade entre estes e suas culturas. Como se observa, as intenções profissionais dos jovens pesquisados confirmam a influência da urbanidade, em que o rural e o urbano aparecem misturados.

Entre os jovens urbanos, 16,97\%, não sabem ou não responderam sobre suas projeções futuras. Entende-se que esses sujeitos sofrem uma crise de identidade recorrente na contemporaneidade e resultante do processo de globalização, em que se evidencia o descentramento da subjetividade. Dessa forma, o índice em análise diz respeito àqueles que não sabem o que esperar do futuro e a suas perspectivas profissionais e pessoais. O segundo maior índice representativo é daqueles que desejam cursar "Medicina Veterinária”, da ordem de 13,33\%. Por ser o de maior representatividade, ele tem muito a dizer sobre a relação da cidade com o campo, pois, ainda que residam na cidade, os jovens estão predispostos a exercer atividades ligadas ao universo rural. Em seguida, vêm Medicina, com 12\%, e Direito, com $9 \%$. Depois há uma diversidade imensa de possibilidades profissionais, muitas delas ligadas ao ambiente urbano, que corresponde a $62 \%$ das respostas. 
Esse índice nos reconduz às discussões levantadas nesta pesquisa. Logo, verifica-se que o imaginário e as projeções profissionais futuras desses jovens são condicionados pelo padrão de sociabilidade. Com efeito, trata-se de sujeitos híbridos que mesclam aspectos culturais rurais e urbanos, mas que vivem a lógica do mundo capitalista, inseridos em um mercado de consumo, o que altera suas percepções sobre trabalho, educação formal em nível superior e modo de vida. Assim, ao "escolherem" uma profissão vinculada ao universo rural (como a Medicina Veterinária, fortemente atrelada, nesse caso, aos cuidados de animais de grande porte ${ }^{6}$ ), é perceptível a mistura de aspectos em seus projetos de estudo e carreira.

De maneira geral, esse dado indica que os jovens moradores da área urbana de Bela Vista de Goiás, assim como os jovens rurais contemplados nesta pesquisa, alimentam uma ruralidade expressa em seu modo de vestir, em sua linguagem e em suas práticas culturais. Diferentemente dos estigmas e dos estereótipos de “atrasados”, “caipiras” e "roceiros”, eles dão um novo significado ao que é ser rural, constroem uma figura pautada na vida urbana, sobre a manutenção do sistema capitalista - são os agroboys e as agrogirls que ensejam o status e o poder que o agronegócio oferece, tal como perceptível na construção identitária de uma juventude goiana, especialmente a que habita as cidades de pequeno porte, como é o caso do município em foco.

Esses jovens oscilam entre o rural e o urbano e, dentro dessa perspectiva, está em curso a construção de uma nova identidade. Segundo Carneiro (1998), os laços que cultuam ainda os prendem à cultura de origem, ao mesmo tempo que eles veem sua autoimagem refletida no espelho da cultura urbana, "moderna", que desponta como referência para a construção de seus projetos para o futuro, geralmente orientados pelo desejo de inserção no mundo moderno.

Ainda sobre a perspectiva de Carneiro (1998), a construção desse projeto modernizador não pode ser vista como originária da atual geração de jovens. Na realidade, trata-se de um valor que assumiu maior hegemonia nas últimas décadas, no decorrer do processo de modernização da sociedade global. Os jovens romperam com o padrão de reprodução do que poderia ser chamado de "cultura camponesa" e não pertencem mais ao universo cultural de seus pais. Com a crescente tecnologia e ampliação do modo de vida urbano, novos padrões de sociabilidade surgiram e (re)configuraram as práticas juvenis.

É verdade que a comunicação entre campo e cidade foi intensificada e o acesso entre os bens e valores urbanos, facilitado. Por isso, os jovens reconstroem

6. Durante a observação participante e na aplicação dos questionários, esse foi um esclarecimento dos entrevistados que assinalaram essa resposta. 
as dinâmicas culturais ancorados em uma releitura dos valores urbanos, em que papéis sociais são redefinidos e projetos são formulados sob novos paradigmas, a partir de uma ruptura (parcial) com os velhos moldes adotados tradicionalmente pela sociedade local.

Contudo, é preciso estabelecer que, ao pensar o rural e urbano, há referência a especificidades culturais bem marcadas. Ambos os lugares comportam jovens com identidades e projetos distintos, o que reitera a heterogeneidade cultural, diluída de um lado e reafirmada de outro, pelo processo de globalização, o que nos impede de traçar recortes homogeneizadores e fronteiras rígidas entre o rural e o urbano, e também dentro de cada um desses polos. No interior desses universos culturais, coexistem sistemas de valores antagônicos que informam os projetos individuais distintos e competitivos.

É certo que o resultado da pesquisa não aponta para a conformação de um todo homogêneo. Assim, não é possível pensar em urbanização do campo como expressão que qualificaria a perda da especificidade de um destes dois polos - campo-cidade ou urbano-rural. Ao contrário, na "modernidade tardia”, onde "[...] não temos outra escolha senão decidir como ser e como agir” (GIDDENS, 1997, p. 94), a possibilidade de escolha como regra seria uma maneira de enfrentar a multiplicidade de opções na vida cotidiana, de modo que estariam abertas as alternativas de ser "rurais" na cidade e "urbanos" no campo (DE PAULA, 1998).

Reafirmam-se, portanto, as dinâmicas culturais embasadas em definições e redefinições de identidades sustentadas não mais na homogeneidade de padrões culturais, mas na diversidade e, principalmente, na maneira específica de combinar práticas e valores originários de universos culturais distintos.

\section{Considerações finais}

Para compreender a realidade dos jovens estudantes do município de Bela Vista de Goiás, em seus contextos rurais e urbanos, lançou-se mão de discussões que permeiam a compreensão da categoria juventude para chegar ao entendimento de que os jovens de uma geração têm comportamentos, pensamentos e ações semelhantes, pois estão num mesmo processo histórico.

É assim que eles dinamizam a cultura. No caso estudado, compreendemos a existência de hibridização cultural e de inter-relação entre os jovens urbanos e rurais como resultado das práticas culturais, em que as formas de ser e o estilo de vida são homogeneizados. Por meio da dicotomia rural-urbano, compreende-se como os jovens da pesquisa podem ser inseridos nos grupos que mesclam aspectos do rural e do urbano, mas que estão sob forte influência urbana, especialmente por conta da mídia e da absorção da tecnologia. Por meio dessa configuração, são 
apresentadas as práticas culturais ressignificadas pelos jovens contemporâneos, em que o caipira sai de cena e entra o agroboy, representação social dos jovens rurais modernos que, numa ótica capitalista e urbanizada, reconfiguram o que é ser do campo.

Por fim, é importante frisar que as bases econômicas do município estudado são alicerçadas nas atividades rurais, assim como acontece com muitos municípios goianos. Os dados da pesquisa de campo apontam para a interpretação das dinâmicas culturais dos jovens rurais e urbanos que, em situações semelhantes, "reproduzem" as mesmas condições de existência. De modo geral, tanto no que tange a um grupo como ao outro, aqueles que moram na área urbana e aqueles que habitam a área rural de Bela Vista de Goiás vivem sob a lógica da modernidade contemporânea. Como é possível visualizar nas respostas da pesquisa quantitativa e na observação participante, predomina uma "negação" do projeto de camponês, em razão de ser atrelado às representações de caipiras. Assim, a pesquisa aponta para a crescente migração dos jovens rurais rumo à cidade e para a permanência dos urbanos na cidade. Logo, conclui-se que os jovens de Bela Vista de Goiás, em seu contexto de ruralidade, vivem o ideal do mundo globalizado. Influenciados pelo ideal do agronegócio, em que agricultura e pecuária estão imbricadas nos capitais financeiro, comercial e industrial, e pela música sertaneja universitária, esses jovens assumem a cultura do agroboy e da agrogirl como forma de vivência modernizante da perspectiva rural.

\section{Referências}

ABRAMO, H. Debate. In: CARNEIRO, M. J.; CASTRO, E. G. de (org.). Juventude rural em perspectiva. Rio de Janeiro: Mauad X, 2007. p. 67-71.

ABRAMOVAY, R. Funções e medidas da ruralidade no desenvolvimento contemporâneo. Rio de Janeiro: Ipea, 2000. p. 1-37. (Texto para discussão, n. 702.)

ADORNO, T. W.; HORKHEIMER, M. A dialética do esclarecimento. Rio de Janeiro: Jorge Zahar, 1985.

BRUMER, A. A problemática dos jovens rurais na pós-modernidade. In: CARNEIRO, M. J.; CASTRO, E. G. de. (org.). Juventude rural em perspectiva. Rio de Janeiro: Mauad X, 2007. p. 35-51.

CANDIDO, A. Os parceiros do Rio Bonito: estudo sobre o caipira paulista e a transformação dos seus meios de vida. 11. ed. Rio de Janeiro: Ouro sobre Azul, 2010.

CARNEIRO, M. J. O ideal rurbano: campo e cidade no imaginário de jovens rurais. In: SILVA, F. C. T.; SANTOS, R.; COSTA, L. F. C. (org.). Mundo rural e política: ensaios interdisciplinares. Rio de Janeiro: Campus, 1998. p. 95-117. 
CARNEIRO, M. J.; CASTRO, E. G. (org.). Juventude rural em perspectiva. Rio de Janeiro: Mauad $\mathrm{X}, 2007$.

CHARLOT, B. Jovens de Sergipe: quem são eles, como vivem, o que pensam. Aracaju: Governo de Sergipe, 2006.

DE PAULA, S. G. O country no Brasil contemporâneo. Revista História, Ciências, SaúdeManguinhos, 1998. Disponível em: https://doi.org/10.159o/S0104-59701998000400015. Acesso em: 14 jul. 2019.

FARIAS, E. Economia e cultura no circuito das festas populares brasileiras. Sociedade e Estado, v. 20, n. 3, p. 647-688, 2005. Disponível em: https://doi.org/10.1590/S010269922005000300007. Acesso em: 22 de março de 2021.

FONSECA, J. J. Metodologia da pesquisa científica. Fortaleza: UEC, 2002.

FORACCHI, M. M. O estudante e a transformação da sociedade brasileira. São Paulo: Nacional. 1965. p. 302.

GIDDENS, A. A vida em uma sociedade pós-tradicional. In: BECK, U.; GIDDENS A. Modernização reflexiva: política, tradição e estética na ordem social moderna. São Paulo, Ed. da Unesp, 1997.

GROPPO, L. A. Juventude: ensaios sobre sociologia e história das juventudes modernas. Rio de Janeiro: Difel, 2000.

HALL, S. Identidade cultural e diáspora. Revista do Patrimônio Histórico e Artístico Nacional. Rio de Janeiro: Iphan, p. 68-75, 1996.

. A identidade cultural na pós-modernidade. Rio de Janeiro: DP\&A, 2000.

IBGE. Instituto Brasileiro de Geografia e Estatística, 2016. Disponível em: http://www.ibge. gov.br. Acesso em: 3 jul. 2019.

MARX, K. O capital: crítica da economia política. Livro I: O processo de produção do capital. Tradução: Regis Barbosa e Flávio R. Kothe. São Paulo: Nova Cultural, 1996. t. 1.

MATOS, A. G. de. Desenvolvimento, autonomia e academia. In: LIMA, D. M de A.; WILKINSON, J. (org.). Inovação nas tradições da agricultura familiar. Brasília, DF: CNPq: Paralelo 15, 2002.

MENASCHE, R.; TORRES, J. C. S.; ESCHER, M. S.; BARGUIL, S. R. Gênero e agricultura familiar: cotidiano da vida e trabalho no leite. Curitiba: Deser: CEMTR/PR, 1996.

MENEZES, I. G. Jovens rurais no sertão sergipano: escolarização e identidades culturais. 2012. 238 f. Dissertação (Mestrado em Educação) - Programa de Pós-graduação em Educação, Universidade Federal de Sergipe, São Cristóvão, Sergipe, 2012.

MIRANDA, C.; SILVA, H. (org.). Concepções da ruralidade contemporânea: as singularidades brasileiras. Brasília: IICA, 2013. v. 21. (Série Desenvolvimento Rural Sustentável).

NOVAES, R. C. Segunda sessão: políticas públicas, direitos e participação. In: CARNEIRO, M. J.; CASTRO, E. G. (org.). Juventude rural em perspectiva. Rio de Janeiro: Mauad X, 2007.

NOVAES, R. R. Juventude e participação social: apontamentos sobre a reinvenção da política. In: ABRAMO, H. W. et. al. (org.). Juventude em debate. São Paulo: Cortez, 2000. 
ORTIZ, R. Mundialização e cultura. São Paulo: Brasiliense, 2006.

PAIS, J. M. Culturas juvenis. Lisboa: Imprensa Nacional Casa da Moeda, 1993.

PREDIGER, S. Estado da arte da situação do jovem rural: a construção de identidades. Revista Anagrama: Revista Cientifica Interdisciplinar da Graduação, ano 3, ed. 1, set.-nov. 2009.

RUA, J. A ressignificação do rural e as relações cidade-campo: uma contribuição geográfica. Revista da Anpege, n. 2, p. 45-66, 2005.

REDIN, E.; SILVEIRA, P. R. C. Juventude rural: experiências e perspectivas. In: SANTOS, V. F.; VELA, H. A. G.; SILVEIRA. P. R. C. Educação rural no mundo contemporâneo. Santa Maria: UFSM, 2012. p. 175-208.

RENK, A. Migrações: de ontem e de hoje. Chapecó: Grifos, 1999.

SETUBAL, M. A. Vivências caipiras. Pluralidade cultural e diferentes temporalidades na terra paulista. São Paulo: Imprensa Oficial, 2005.

SILVA, P. S.; DINIZ FILHO, E. T.; MARACAJA, P. B.; PEREIRA, T. F. C. Agricultura familiar: um estudo sobre a juventude rural no município de Serra do Mel - RN. Revista Verde, v. 1, n. 1, p. 54-66, 2006.

SINGER, P. A juventude como coorte: uma geração em tempos de crise social. In: ABRAMO, H. W.; BRANCO, P. P. M. (org.). Retratos da juventude brasileira: análises de uma pesquisa nacional. São Paulo: Instituto Cidadania; Fundação Perseu Abramo, 2005. p. 27-35.

SOUZA, R. A. Além dos muros: razão ou razões na escola? In: CAVALCANTE, M. H. K.; SOUZA, R. A. (org.). Culturas juvenis: dinamizando a escola. Porto Alegre: ediPUCRS, 2009.

WANDERLEY, M. de N. B. O mundo rural brasileiro: acesso a bens e serviços e integração campo-cidade. Estudos Sociedade e Agricultura, v. 17, n. 1, p. 60-85, abr. 2009.

WEISHEIMER, N. Sobre a invisibilidade social das juventudes rurais. Desidades, ano 1, n. 1, dez. 2013.

- Situação juvenil e projetos profissionais de jovens agricultores familiares no Recôncavo da Bahia. Estudos Sociedade e Agricultura, v. 27, n. 1, p. 67-94, fev. 2019.

WILLIAMS, R. O campo e a cidade: na história e na literatura. São Paulo: Companhia das Letras, 1989. 


\section{Andréa Vettorassi}

Doutora em Sociologia pela Universidade Estadual de Campinas (Unicamp), com mestrado e bacharelado em Ciências Sociais pela Universidade Federal de São Carlos (UFSCar). Professora adjunta de Sociologia da Universidade Federal de Goiás (UFG), Faculdade de Ciências Sociais e Programa de Pós-graduação em Sociologia e membro do Núcleo de Estudos sobre Trabalho e da Cátedra Sérgio Vieira de Mello da mesma universidade.

Email: avettorassi@ufg.br

ORCID: 0000-0002-5615-4100

Contribuição de autoria: conceituação; curadoria de dados; análise formal; obtenção de financiamento; metodologia; administração do projeto; supervisão/ orientação; escrita - revisão e edição.

\section{Lorrany dos Santos Ferreira}

Graduada em Ciências Sociais pela Universidade Federal de Goiás (UFG), mestra em Sociologia e especialista em História e Narrativas Audiovisuais pela mesma instituição.

Email: ferreiralorrany@hotmail.com

ORCID: 0000-0001-6883-9599

Contribuição de autoria: conceituação; curadoria de dados; obtenção de financiamento; investigação/pesquisa; metodologia; escrita - primeira redação. 


\section{Flávio Munhoz Sofiati}

Doutor em Sociologia pela Universidade de São Paulo (USP), mestre em Ciências Sociais pela Universidade Federal de São Carlos (UFSCar) e bacharel em Ciências Sociais pela Universidade Estadual Paulista Júlio de Mesquita Filho (Unesp). Professor associado de Sociologia da Universidade Federal de Goiás (UFG), Faculdade de Ciências Sociais, Programa de Pós-graduação em Sociologia e Programa de Pós-graduação em Antropologia Social. Membro do Observatório Juventudes na Contemporaneidade e do Núcleo de Estudos de Religião Carlos Rodrigues Brandão.

Email: flavio_sofiati@ufg.br

ORCID: 0000-0002-6422-4471

Contribuição de autoria: curadoria de dados; análise formal; validação; visualização; escrita - revisão e edição.

Submissão: 26 de junho de 2020.

Aprovação: 3 de fevereiro de 2021.

Como citar: VETTORASSI, A.; FERREIRA, L. S.; SOFIATI, F. Juventudes entre o rural e o urbano: o caso dos agroboys e agrogirls de Bela Vista de Goiás. Revista brasileira de estudos urbanos e regionais. v. 23, E202112pt, 2021. DOI 10.22296/2317-1529.rbeur.202112pt

Artigo licenciado sob Licença Creative Commons CC BY 4.0.

https://creativecommons.org/licenses/by/4.o/deed.pt_BR 